Electronic Supporting Information

for

\title{
Oxygen Transport Routes in Ionomer Film on Polyhedral Platinum Nanoparticles
}

\author{
Linhao Fan, ${ }^{\mathrm{a}, \mathrm{b}}$, Yun Wang, ${ }^{\mathrm{b}, *}$, Kui Jiao ${ }^{\mathrm{a}, *}$
}

a State Key Laboratory of Engines, Tianjin University, 135 Yaguan Road, Tianjin 300350, China

b Renewable Energy Resources Laboratory, Department of Mechanical and Aerospace Engineering, University of California, Irvine, CA 92697-4075, USA

*Corresponding author: yunw@uci.edu; kjiao@tju.edu.cn 

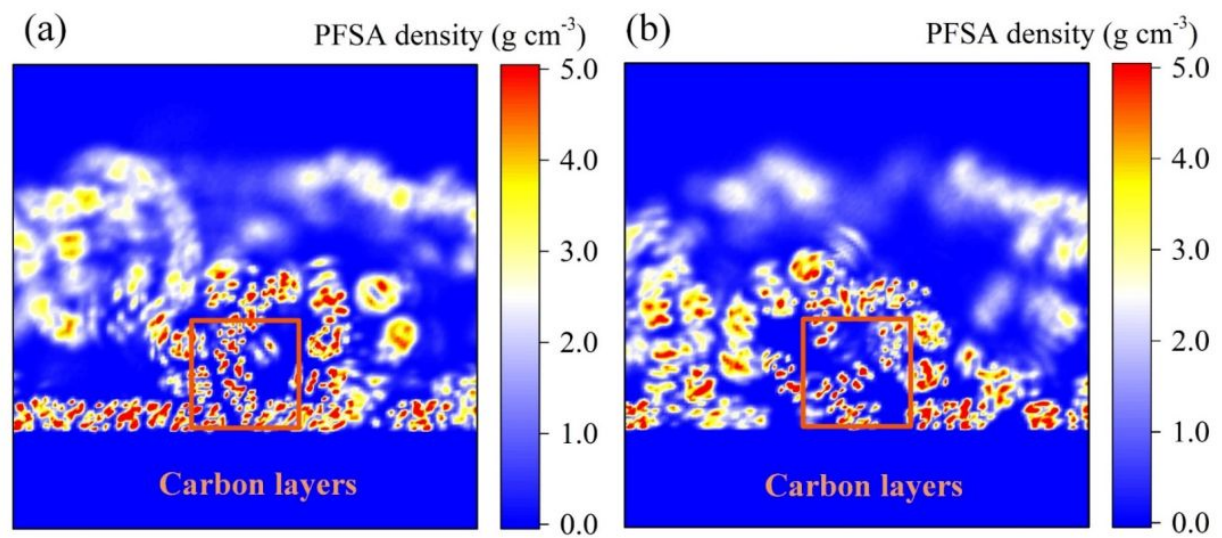

(c)

PFSA density $\left(\mathrm{g} \mathrm{cm}^{-3}\right)$
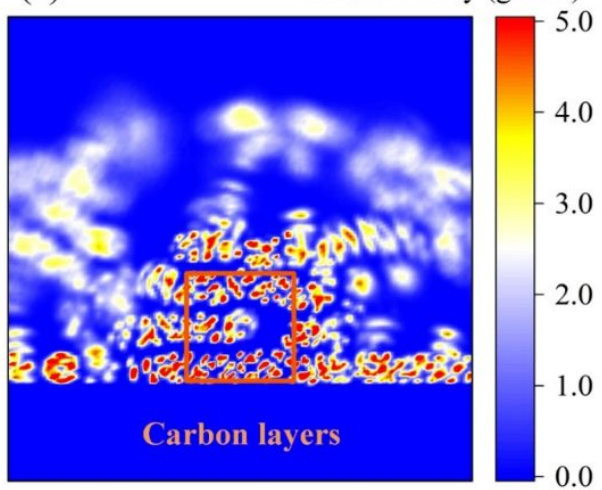

\section{(d)}

PFSA density $\left(\mathrm{g} \mathrm{cm}^{-3}\right)$

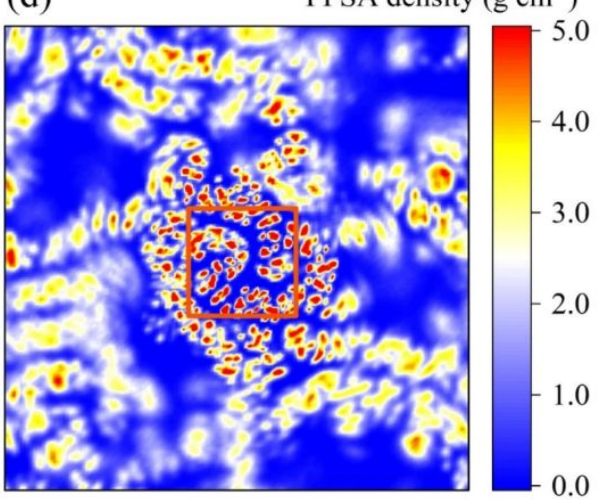

Figure S1. Two-dimensional PFSA density distributions by averaging the density of the regions within $0.725 \mathrm{~nm}$ from $\mathrm{f}_{\mathrm{c} 1}(\mathrm{a}), \mathrm{f}_{\mathrm{c} 2}(\mathrm{~b}), \mathrm{f}_{\mathrm{c} 3}(\mathrm{c})$ and $\mathrm{f}_{\mathrm{c} 5}(\mathrm{~d})$ planes (Figure 2) for the cubic Pt nanoparticle, respectively.

(a)

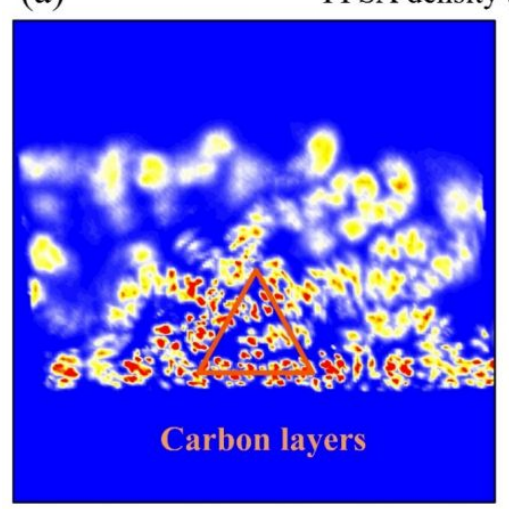

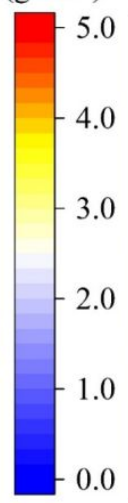

(b) PFSA density $\left(\mathrm{g} \mathrm{cm}^{-3}\right)$

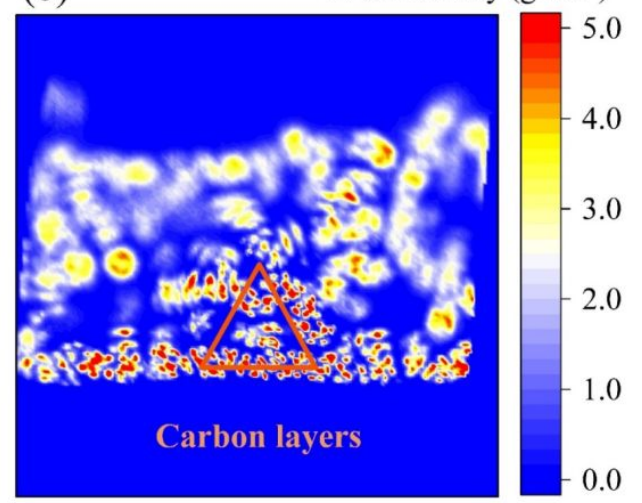

Figure S2. Two-dimensional PFSA density distributions by averaging the density of the regions within $0.725 \mathrm{~nm}$ from $\mathrm{f}_{\mathrm{t} 1}(\mathrm{a})$ and $\mathrm{f}_{\mathrm{t} 3}(\mathrm{~b})$ planes (Figure 2) for the tetrahedral Pt nanoparticle, respectively. 

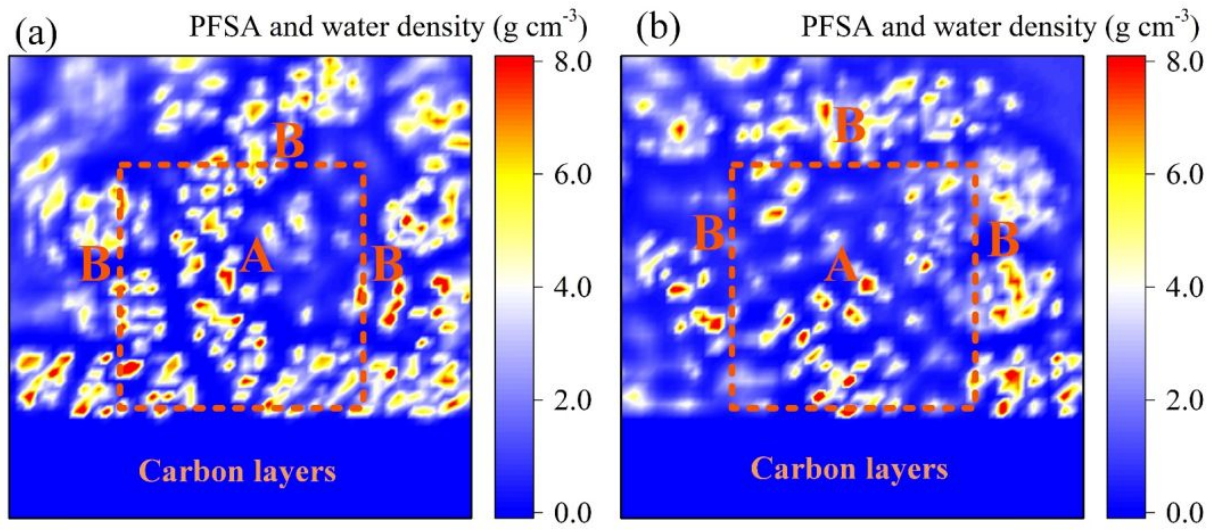

(c) PFSA and water density $\left(\mathrm{g} \mathrm{cm}^{-3}\right)$

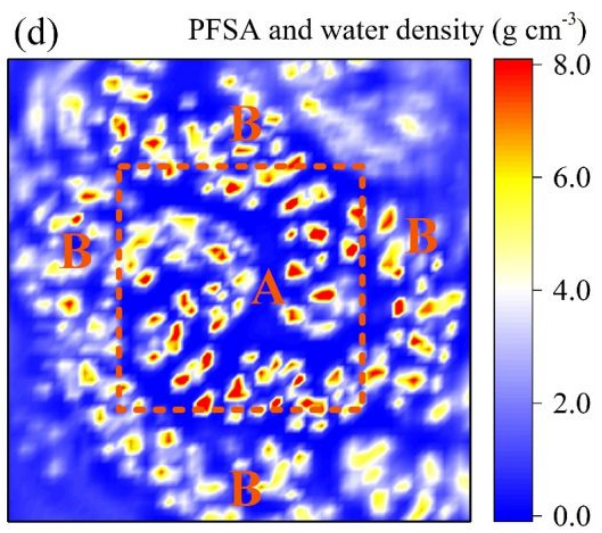

Figure S3. Two-dimensional ionomer (PFSA and water) density distributions by averaging the density of the regions within $0.725 \mathrm{~nm}$ from $\mathrm{f}_{\mathrm{c} 1}(\mathrm{a}), \mathrm{f}_{\mathrm{c} 2}(\mathrm{~b}), \mathrm{f}_{\mathrm{c} 3}(\mathrm{c})$ and $\mathrm{f}_{\mathrm{c} 5}(\mathrm{~d})$ planes for the cubic Pt nanoparticle, respectively.

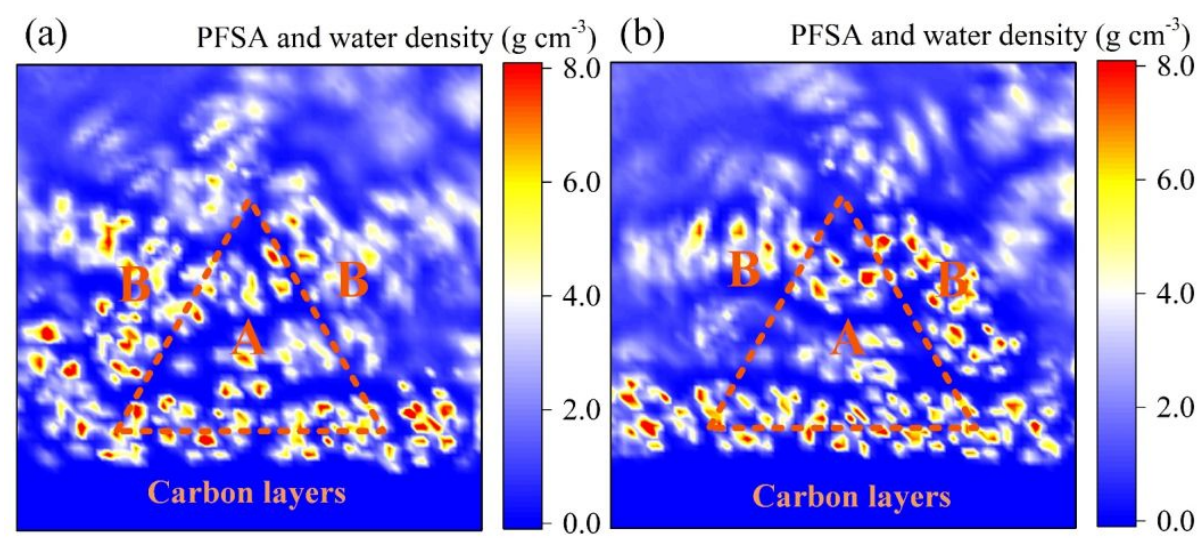

Figure S4. Two-dimensional ionomer (PFSA and water) density distributions by averaging the density of the regions within $0.725 \mathrm{~nm}$ from $\mathrm{f}_{\mathrm{t} 1}$ (a) and $\mathrm{f}_{\mathrm{t} 3}$ (b) planes for the tetrahedral Pt nanoparticle, respectively. 

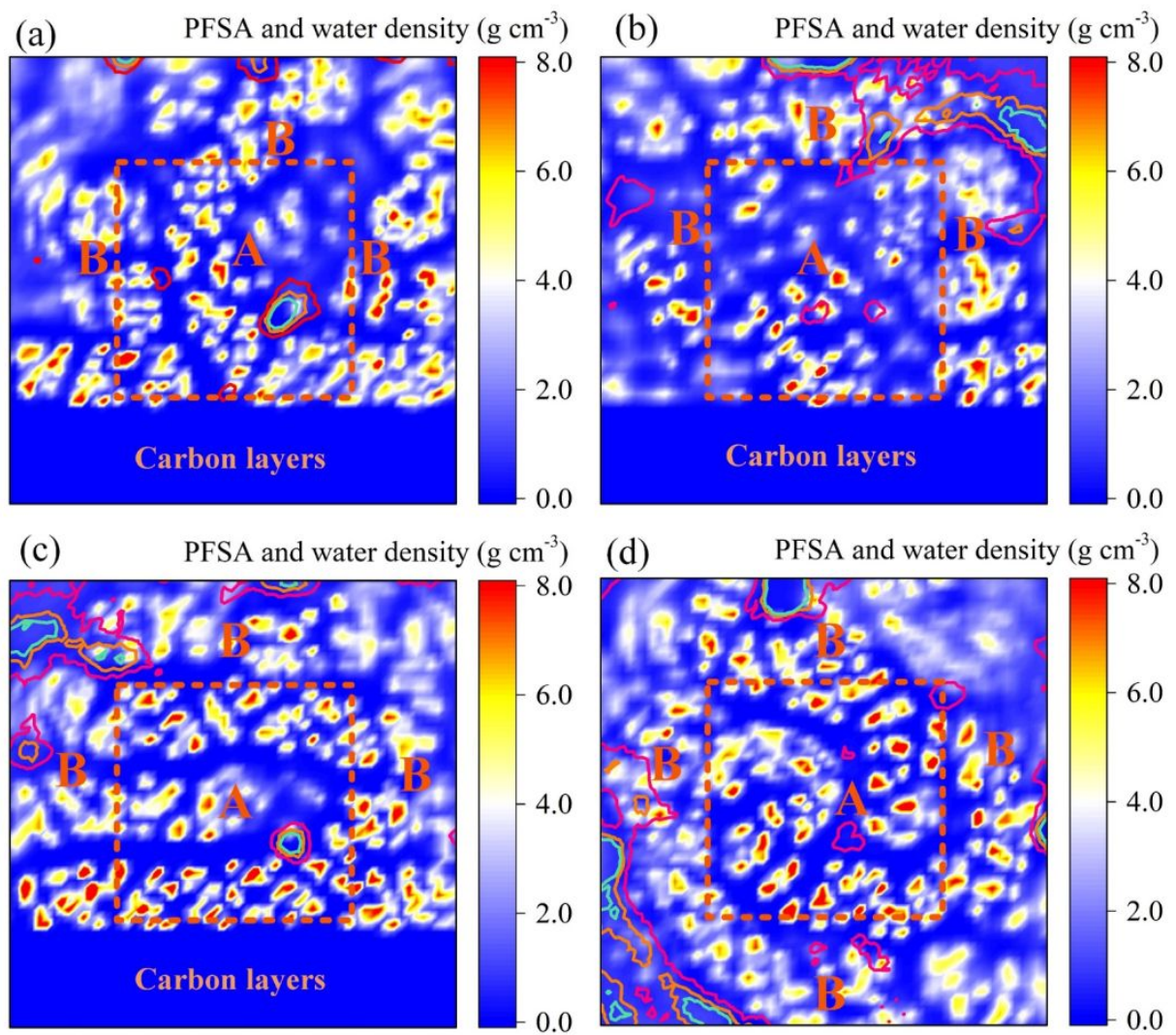

Figure S5. Two-dimensional ionomer (PFSA and water) and $\mathrm{O}_{2}$ density distributions by averaging the density of the regions within $0.725 \mathrm{~nm}$ from $f_{c 1}(a), f_{c 2}(b), f_{c 3}(c)$ and $f_{c 5}(d)$ planes for the cubic Pt nanoparticle, respectively. The color-filled contours represent the ionomer density distributions, while the pink, orange and green lines are the $\mathrm{O}_{2}$ density contours at $0.02,0.06$ and $0.1 \mathrm{~g} \mathrm{~cm}^{-3}$, respectively.

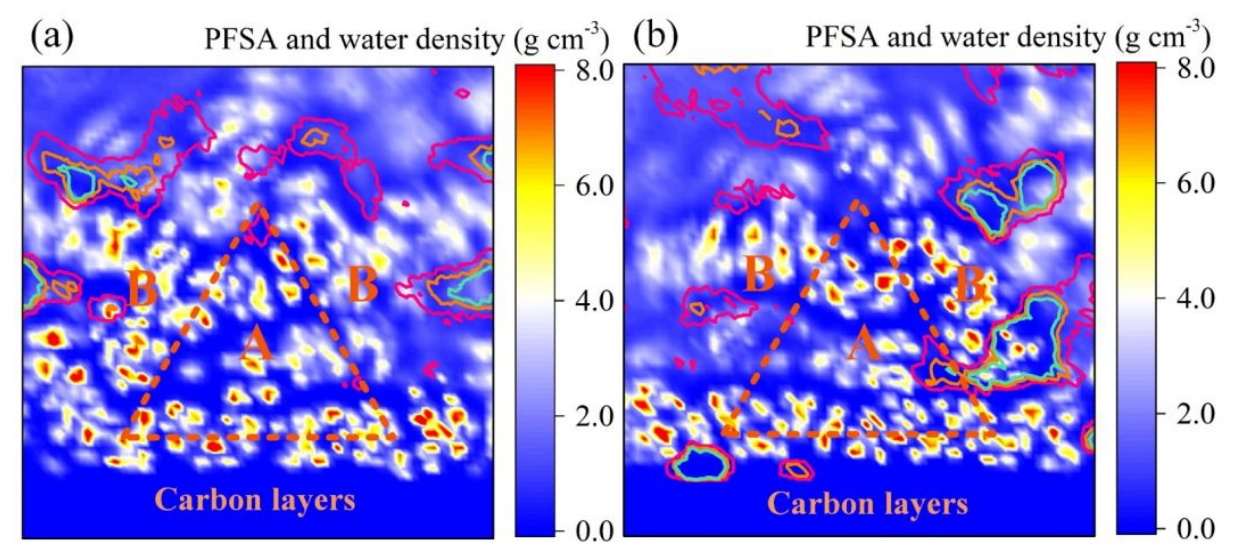

Figure S6. Two-dimensional ionomer (PFSA and water) and $\mathrm{O}_{2}$ density distributions by averaging the density of the regions within $0.725 \mathrm{~nm}$ from $\mathrm{f}_{\mathrm{t} 1}(\mathrm{a})$ and $\mathrm{f}_{\mathrm{t} 3}$ (b) planes for the tetrahedral Pt nanoparticle, respectively. The color-filled contours represent the ionomer 
density distributions, while the pink, orange and green lines are the $\mathrm{O}_{2}$ density contours at 0.02 , 0.06 and $0.1 \mathrm{~g} \mathrm{~cm}^{-3}$, respectively.
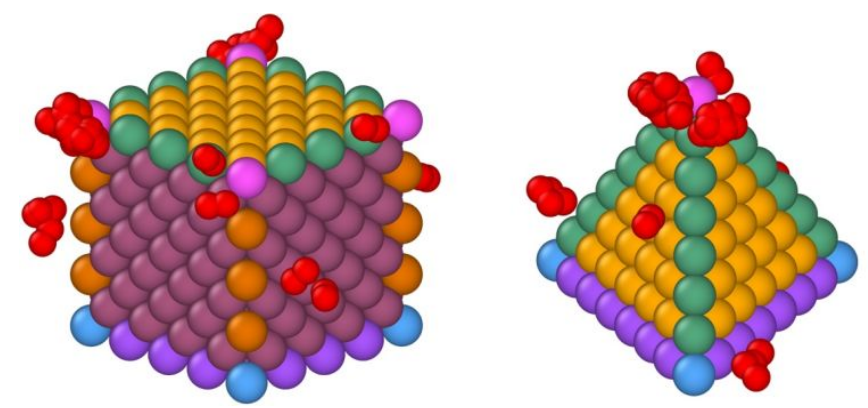

Figure S7. Snapshots of the $\mathrm{O}_{2}$ molecules (red beads) that reach the Pt nanoparticles during 1025 ns. The meanings of the different bead colors of Pt nanoparticles are given in Figure 8.

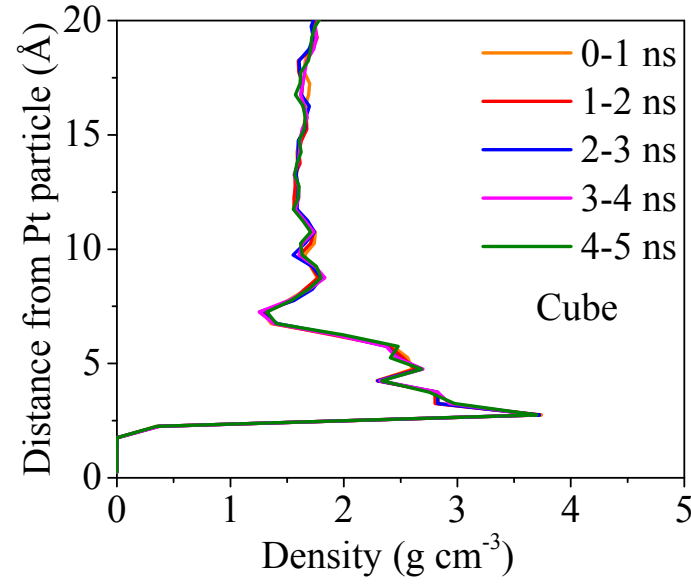

(a)

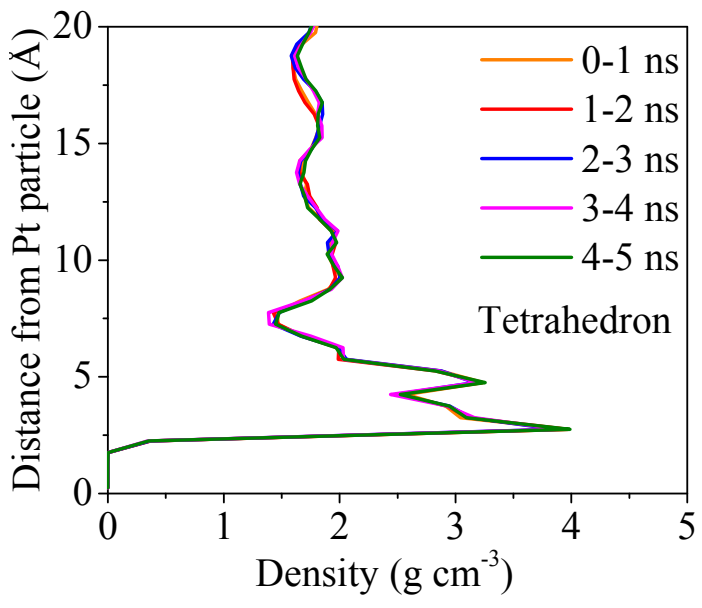

(c)

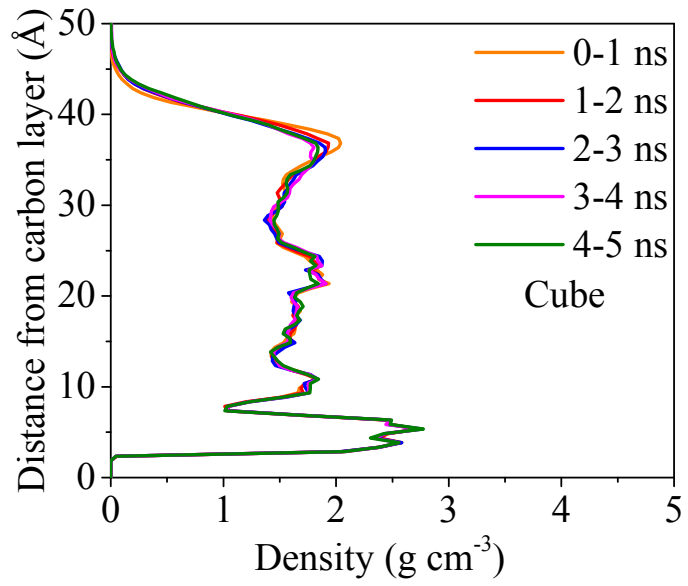

(b)

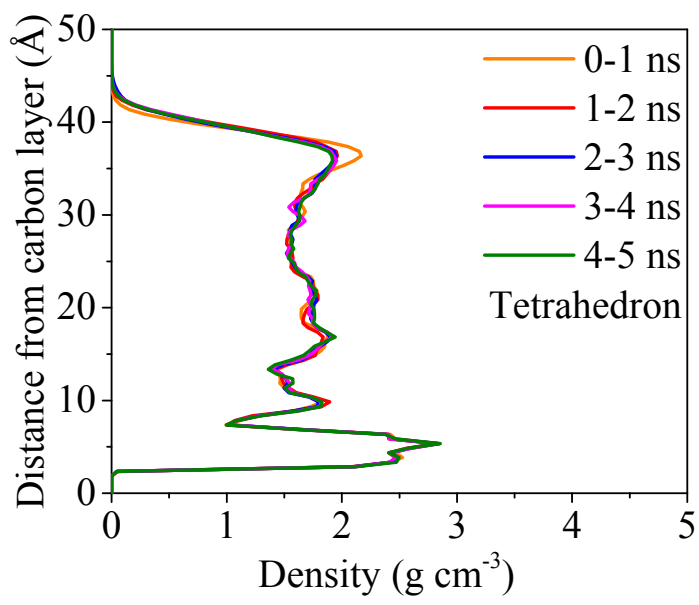

(d)

Figure S8. Ionomer density distributions at different distances from the outer shell of Pt nanoparticles ( $a$ and $c$ ) and the upper carbon layer (b and d) for the cubic ( $a$ and b) and tetrahedral (c and d) cases during a 5-ns NVT simulation. 


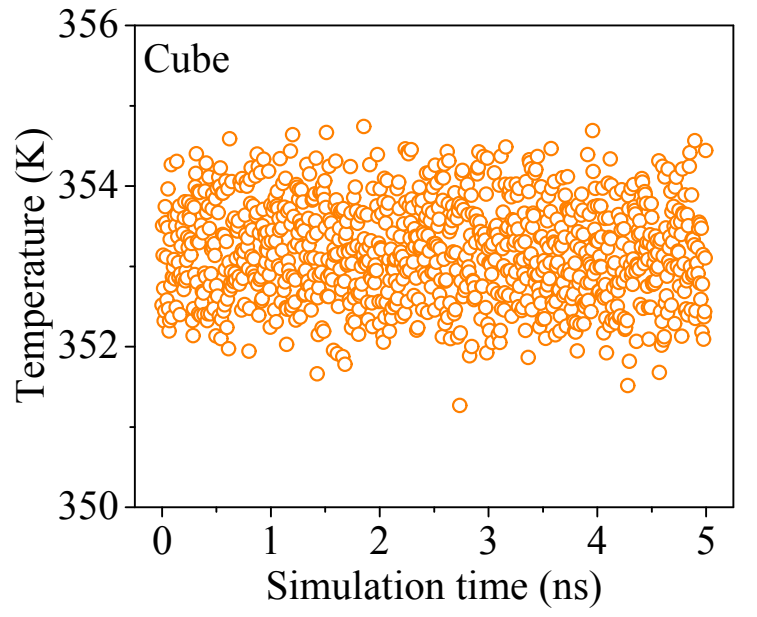

(a)

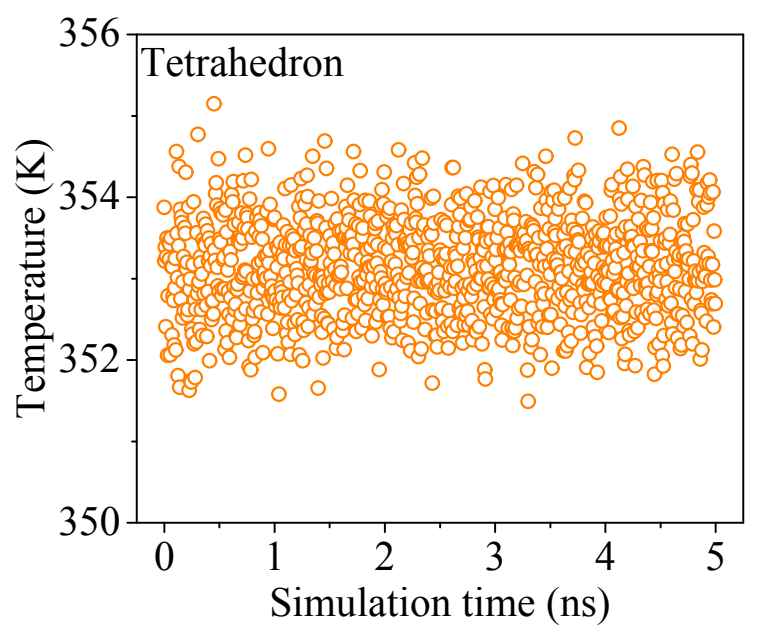

(b)

Figure S9. System temperatures for the cubic (a) and tetrahedral (b) cases during a 5-ns NVT simulation.

The ionomer density and temperature data in Figures S8 and S9 are sampled every 2 ps and $0.01 \mathrm{ps}$ for $5 \mathrm{~ns}$, respectively, and then the values are averaged every $1 \mathrm{~ns}$ and $1 \mathrm{ps}$, respectively. As shown in Figures S8 and S9, the average density distributions don't change over time and the temperature is well controlled around $353 \mathrm{~K}$, both of which demonstrate the configurations reach equilibrium. 